\title{
Hemophagocytic lymphohistiocytosis and myelodysplastic syndrome: a case report and review of the literature
}

\author{
Y. Sun ${ }^{1}$, C. Blieden ${ }^{2}$, B. Y. Merritt ${ }^{3}$, R. Sosa ${ }^{1,4}$ and Gustavo Rivero ${ }^{1,4^{*}}$ (i)
}

\begin{abstract}
Background: Hemophagocytic lymphohistiocytosis $(H L H)$ is characterized by hyperinflammation and life-threatening cytopenias. Survival is poor, and management is pivotal on rapid identification of the disease. HLH is associated with hematologic malignancies, however correlation with myelodysplastic syndromes (MDS) is exceedingly unusual. Although minimizing overwhelming hyperinflammation by treating hemophagocytosis are central for HLH outcome, there is urgent necessity to identify potential initiating mechanisms that could assist in therapy design.

Case description: Here, we describe an elderly African American patient who developed rapid onset of cytopenias and coagulopathy associated with hepatic and bone marrow hemophagocytosis. We analyze four additional similar cases to isolate clinical, laboratory and cytogenetic findings expected in patients exhibiting concurrent HLH and MDS. HLH linked with MDS retains common HLH features associated with systemic hyperinflammation such as fever, hypotension, hepatosplenomegaly, hyperferritinemia, coagulopathy and rapidly evolving cytopenias. Typical MDS chromosomic abnormality such as trisomy 8 was frequently observed in our studied cases.
\end{abstract}

Conclusion: Our case describes difficulties while managing HLH in MDS patients. Diagnosis should be based on identifying $\mathrm{HLH}$ appropriate criteria and if possible karyotypic abnormalities normally observed in MDS.

Keywords: Hemophagocytic lymphohistiocytosis, Myelodysplastic syndrome, Hyperinflammation

\section{Introduction}

Hemophagocytic lymphohistiocytosis (HLH) is characterized by deregulated immunity and end organ damage. Primary HLH is linked with autosomal recessive and $\mathrm{X}$-linked mutations. Secondary HLH results from predisposing conditions. Both primary and secondary HLH may be activated by an infections and malignancies. [1] The association of HLH with hematologic malignancies is accepted. However, HLH initiated by myelodysplastic syndrome (MDS) is exceedingly unusual. Although dysplasia is observed in patients with hemophagocytosis,

*Correspondence: garivero@bcm.edu

${ }^{4}$ The Dan L. Duncan Comprehensive Cancer Center at Baylor College of Medicine, 1 Baylor Plaza, Houston, TX 77030, USA

Full list of author information is available at the end of the article a hyperinflammatory entity characterized by dysplastic cytopenias, MDS like karyotypic abnormality and hemophagocytosis suggests a different spectrum of disease, in which HLH originates from a clonal disorder. In this report, we present an elderly female who fulfilled HLH 2004 criteria exhibiting erythroid and megakaryocytic dysplasia associated with trisomy $8[+8]$. Additionally, we examine published cases in English literature to identify clinical, laboratory and cytogenetic features observed in MDS patients fulfilling HLH 2004 criteria.

\section{Case presentation}

An 83-year-old African American female presented with lethargy, temperature of $102.9^{\circ} \mathrm{F}$ and tachycardia. After 9 days of broad-spectrum antibiotics, she developed hemodynamic instability requiring vasopressors, original author(s) and the source, provide a link to the Creative Commons licence, and indicate if changes were made. The images or other third party material in this article are included in the article's Creative Commons licence, unless indicated otherwise in a credit line to the material. If material is not included in the article's Creative Commons licence and your intended use is not permitted by statutory regulation or exceeds the permitted use, you will need to obtain permission directly from the copyright holder. To view a copy of this licence, visit http://creativecommons.org/licenses/by/4.0/. The Creative Commons Public Domain Dedication waiver (http://creativeco mmons.org/publicdomain/zero/1.0/) applies to the data made available in this article, unless otherwise stated in a credit line to the data. 
worsening liver function (peak bilirubin of $12.5 \mathrm{mg} / \mathrm{dL}$, Aspartate aminotransferase (AST) of $689 \mathrm{IU} / \mathrm{L}$, Alanine aminotransferase (ALT) of $239 \mathrm{IU} / \mathrm{L}$ ) and leukocytosis of $16,000 / \mathrm{uL}$. Her hemoglobin was $8.9 / \mathrm{uL}$ and platelets had fallen to $26,000 / \mathrm{uL}$. Disseminated intravascular coagulation (DIC) was considered given progressive severe thrombocytopenia of 13,000 U/L, fibrinogen $<70 \mathrm{mg} / \mathrm{dL}$ and d-dimer of $12.4 \mathrm{mg} / \mathrm{L}$. Her ferritin was $9479 \mathrm{ng} / \mathrm{mL}$ and fasting triglycerides (TAG) were 321 $\mathrm{mg} / \mathrm{dL}$. Soluble interleukin-2R $\alpha$ (CD25) was $<38 \mathrm{pg} / \mathrm{dL}$. Her human immunodeficiency virus (HIV), rapid influenza $A / B$, hepatitis $B / C$ serologies were all negative. Epstein-barr virus (EBV) viral load was negative. Given concern autoimmune hepatitis, a liver biopsy showed Kupffer cell hypertrophy with hemophagocytosis. Bone marrow biopsy demonstrated hemophagocytosis (Fig 1a, b). In addition, significant erythroid nuclear fragmentation and karyorrhexis were observed (Fig 1c). Marrow cytogenetics showed 47, XX +8 [6], 46, XX [5]. Next generation sequencing (NGS) including CSFR1, SF3B1, SRSF2, U2AF1, NRAS, KRAS, FLT3, JAK2, KIT, PHF6, PDGFRA, CDKN2A, IDH1, IDH2, TET2, EZH2, CEBPA, EP300, PTPN11, P53, CREBBP, IKZF1, IKZF3, NOTCH1, RUNX1, WT1 and NPM1 showed DNMT3A p.Arg736His (c.2207G>A) and DNMT3A p.Leu859Ter (c.2576T $>$ A) at allele frequencies of 2.7 and $2.4 \%$, respectively. In view of her hemophagocytosis, cytopenias, high temperature, abnormal liver function test, low fibrinogen and elevated fasting triglycerides and ferritin, she fulfilled 5/8 HLH 2004 criteria. HLH-94 regimen was initiated with dexamethasone and etoposide. She developed neutropenic sepsis and etoposide was stopped. Blood cultures were positive for Escherichia coli. Patient expired after developing hemodynamic instability.

\section{Methods}

In addition to our case, three additional previously published reports were included in our reviewed cases. Clinical, laboratory and karyotypic data was analyzed to investigate potential features commonly observed in patients presenting with hyperinflammation and MDS. Data aggregation from four cases presenting with $\mathrm{HLH}$ and MDS allowed identification of clinical outcome in patients receiving HLH directed therapy or alternative regimens.

\section{Cohort analysis}

$\mathrm{HLH}$ is a deadly syndrome. If untreated, survival is less than 2 months [2]. Here, we describe an elderly female exhibiting hyperinflammation, refractory cytopenias, erythroid dysplasia, expansion of +8 metaphases and bone marrow/hepatic hemophagocytosis suggesting HLH associated with MDS (HLH-MDS). In addition to our patient, three previously published HLH cases associated with MDS were included in study cohort (Table 1 ). $7 / 8 \mathrm{HLH}$ criteria were observed in two $(50 \%)$, and one (25\%) case with $6 / 8$ and $5 / 8$ criteria, each. Our report and published cases are novel since 3 of 4 (75\%) patients harbored a karyotypic abnormality highlighting the clonal nature of the disease. A detectable chromosomic abnormality suggests that HLH was systemically initiated by MDS rather than representing a reactive phenomenon [3-5]. In reviewed cases, patients were older than 60 years with exception of one pediatric patient. International prognostic score system (IPSS) was intermediate- 1 and high-risk ( 2 cases, each). +8 was detected as sole abnormality or within a complex metaphase in $75 \%$ of cases. Most of the patients succumbed to the disease, except one case treated with high dose methylprednisolone, cyclosporine (CSA) decitabine. Tamamyan et al.

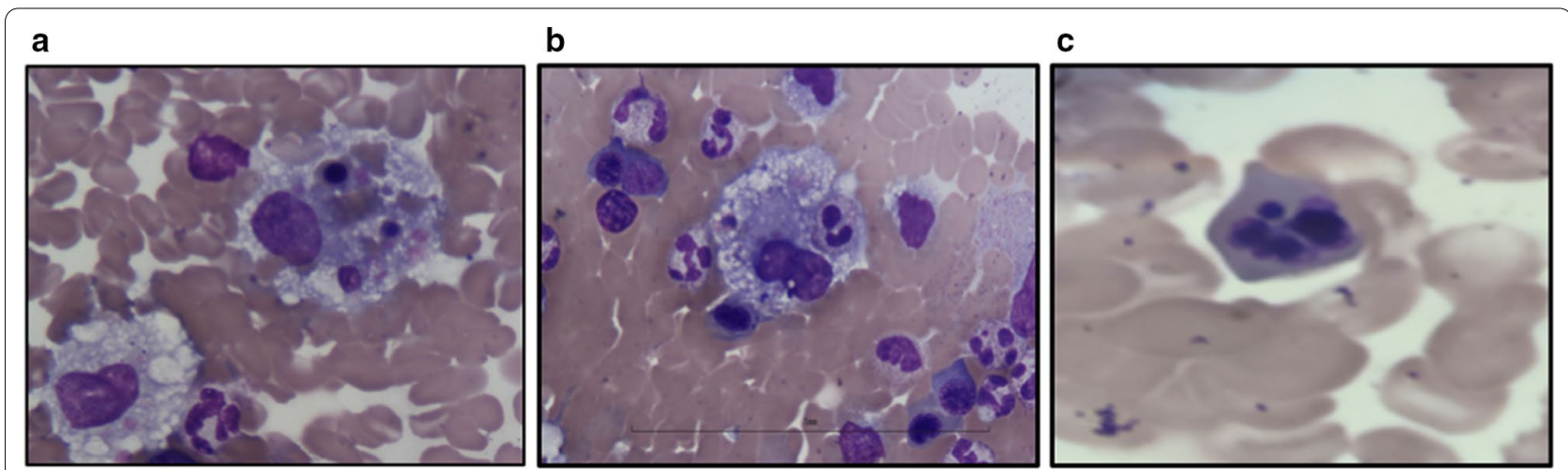

Figure 1. Bone marrow hemophagocytosis and dysplastic changes in a trisomy 8 myelodysplastic syndrome patient. a Bone marrow aspirate smear revealing active hemophagocytosis. Erythroid cells are phagocytized by histiocytic cells. $\mathbf{b}$ Bone marrow aspirate showing neutrophil phagocytized by histiocytic cell. Peripherally to hemophagocytosis, erythroid precursor shows megaloblastic changes. Additionally, hyposegmented neutrophils are observed. c Nucleated red cell showing nuclear fragmentation with dysmorphic features suggesting dysplasia 


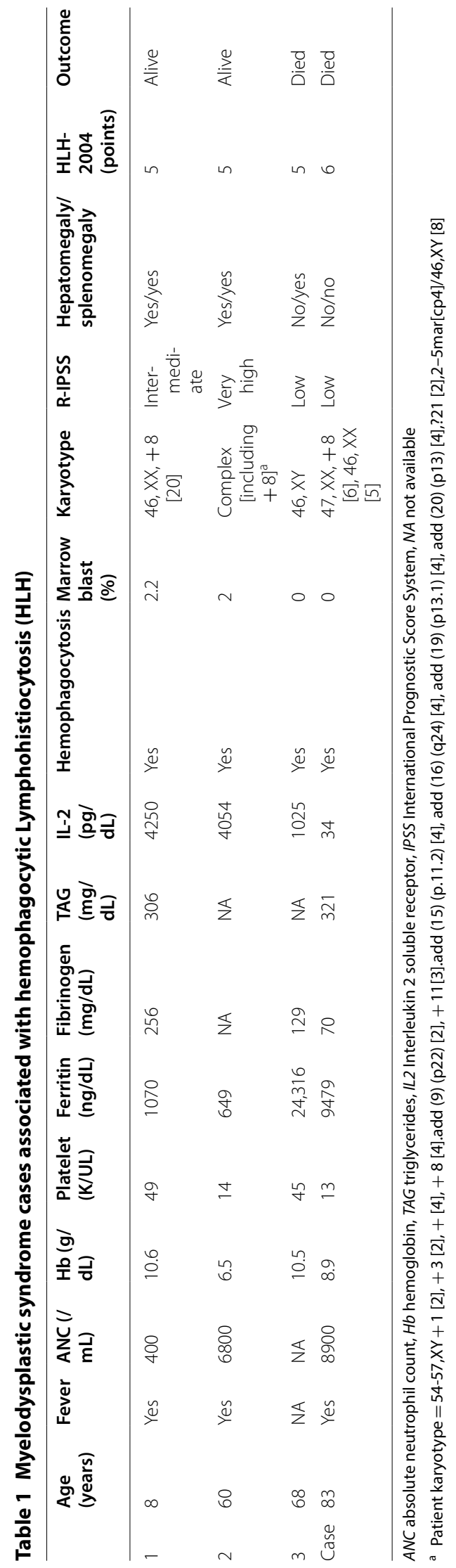


described 33 cases of HLH, of which 3(9\%) exhibited concurrent MDS, although only one was identified by HLH 2004 [6]. Karyotypic abnormalities were not reported. As in our case, the author reported that HLH linked with MDS represented a fatal condition.

\section{Conclusions}

Efforts to elucidate pathogenesis of HLH demonstrate that expansion of $\mathrm{CD}^{+}$cytotoxic $\mathrm{T}$ cells, low Treg frequencies and cytokine storm are frequently observed [7]. In MDS, similar clonal $\mathrm{T}$ cell expansion and decreased Treg frequencies results in stem cell/progenitor apoptosis in low-risk disease. Rather than hyperinflammation normally found in HLH patients, chronic low-grade inflammation develops associated with tumor-necrosis factor-alpha (TNF- $\alpha$ ), interleukin 1-beta (IL-1 $\beta$ ) and IL-6 upregulation. Cytokine abnormalities in MDS leads to increased apoptosis and marrow hypercellularity. However, decreased marrow cellularity can develop in fraction of MDS patients harboring trisomy 8 karyotypic abnormality. Interestingly, our patient and two previously published cases harbored +8 in their metaphase analysis at MDS diagnosis while HLH had developed $[3,5]$. +8 cells induce autologous T-cell oligoclonal expansion capable to target MDS precursor/progenitors resulting in characteristic marrow hypoplasia $[8,9]$. In most of MDS cases, disease propagation depends on somatic mutations acquisition allowing dysplastic transformation. Mutations in perforin-dependent cytotoxicity are classically described in primary HLH. In our case, it is conceivable that myeloid mutations induced apoptotic and differentiation defects, and "facilitated" acquisition of HLH-like phenotype.

The preferred HLH treatment is HLH-94 protocol, but its administration is limited by MDS-induced cytopenias, as was the case with our patient. This is largely due to hemopoietic progenitor depletion initiated MDS and likely aggravated by HLH. Daitoku et al. reports superior outcome in a HLH-MDS patient treated with Methylprednisolone, CSA and decitabine[4]. Indeed, in vivo administration of hypomethylating agents (HMA) induce Foxp3+ Tregs expansion leading to immune suppression, and attenuates graft-versus-host disease [10]. The combination of HMA and immunosuppressive therapy may be promising treatment in HLH-MDS cases as suggested by the interesting outcomes in the case described by Daitoku et al.

We acknowledge limitations to our interpretation. It is possible that hyperinflammation initiated by HLH led to marrow dysplasia. However, the evidence of +8 strongly suggests a clonal etiology supporting MDS induced HLH. Secondly, sequencing did not include HLH like mutations such as PRF1, STX11, UNC13D, STXBP2, RAB27A,
SH2D1A, BIRC4, LYST, ITK, SLC7A7, XMEN, HPS, among others. This may affect our ability to assign HLH as culprit for hyperinflammation in our case. However, Rui et al. recently demonstrated that epigenetic perturbations induced by DNMT3A mutations results in aberrant stem cell gene-expression associated with immune deregulation, which may have contributed to inflammatory manifestations in our case [11]. Additionally, recent data demonstrated that myeloid specific mutations including TET2, ASXL1, and DNMT3A can induce inflammasome activation in myelodysplasia and exacerbate inflammation [12-15]. In summary, HLH associated with MDS is an aggressive entity and should prompt careful evaluation hyperinflammatory signs. It is possible that targeting MDS hematopoiesis with hypomethylating agents in combination with immunosuppressive therapy to minimize hyperinflammation could improve life-threatening HLH in MDS patients.

\section{Abbreviations}

HLH: Hemophagocytic lymphohistiocytosis; MDS: Myelodysplastic syndrome; HMA: Hypomethylating agent.

\section{Acknowledgements}

Financial support for this study was provided by the Texas Golfers against Cancer grant funding.

\section{Authors' contribution}

YS and GR contributed equally to manuscript writing. BYM sequenced marrow cells and provided analysis for next generation sequencing. CB provided morphologic details of marrow. GR, YS and RS designed plan for investigation and report of the case and studied cohort. RG conceived the study; RG and SY designed the research; RG, SY, MBY, RS, BC performed the research; RG and $S Y$ analysed and interpreted the results; $R G, S Y, M B Y, R S$ and $B C$ wrote, reviewed and approved the manuscript. All authors read and approved the final manuscript.

Funding

Not applicable.

\section{Availability of data and supporting materials}

The datasets used and/or analysed during the current study are available from the corresponding author on reasonable request.

\section{Ethic approval and consent to participate}

Institutional Review Board (IRB) approval was obtained for publication.

\section{Consent for publication}

Written informed consent was obtained from the patient for publication of this case report and any accompanying images. A copy of the written consent is available for review by the Editor-in-Chief of this journal.

\section{Competing interest}

Dr. Sun, Dr. Blieden, Dr. Merritt, Dr. Sosa and Dr. Rivero reported no conflict of interest.

\section{Author details}

1 Section of Hematology/Oncology, Baylor St Luke Medical Center, Houston, TX 77030, USA. ${ }^{2}$ Department of Molecular and Human Genetics, Baylor Genetics, Baylor College of Medicine, Houston, TX, USA. ${ }^{3}$ Department of Pathology and Immunology, Baylor St. Luke's Medical Center, Baylor College of Medicine, Houston, TX, USA. ${ }^{4}$ The Dan L. Duncan Comprehensive Cancer Center at Baylor College of Medicine, 1 Baylor Plaza, Houston, TX 77030, USA. 
Received: 30 October 2020 Accepted: 8 December 2020

Published online: 01 March 2021

\section{References}

1. Filipovich $\mathrm{AH}$, Chandrakasan S. Pathogenesis of hemophagocytic lymphohistiocytosis. Hematol Oncol Clin North Am. 2015;29(5):895-902.

2. Otrock ZK, Eby CS. Clinical characteristics, prognostic factors, and outcomes of adult patients with hemophagocytic lymphohistiocytosis. Am J Hematol. 2015:90(3):220-4.

3. Kim SH, Yi DY, Lee NM, Yun SW, Chae SA, Lim IS. A rare case of hemophagocytic lymphohistiocytosis associated with myelodysplastic syndrome and trisomy 8 in a pediatric patient. J Pediatr Hematol Oncol. 2019:41(1):57-9.

4. Daitoku S, Aoyagi T, Takao S, Tada S, Kuroiwa M. Successful treatment of hemophagocytic lymphohistiocytosis associated with low-risk myelodysplastic syndrome by azacitidine. Intern Med. 2018;57:2995-9.

5. Tsuji T, Yamasaki H, Arima N, Tsuda H. Hemophagocytic lymphohistiocytosis associated with myelodysplastic syndromes. Int J Hematol. 2010;92(3):547-9.

6. Tamamyan GN, Kantarjian HM, Ning J, Jain P, Sasaki K, McClain KL, et al. Malignancy-associated hemophagocytic lymphohistiocytosis in adults: relation to hemophagocytosis, characteristics, and outcomes. Cancer. 2016;122(18):2857-66

7. Humblet-Baron S, Franckaert D, Dooley J, Bornschein S, Cauwe B, Schonefeldt $\mathrm{S}$, et al. IL-2 consumption by highly activated CD8 T cells induces regulatory T-cell dysfunction in patients with hemophagocytic Iymphohistiocytosis. J Allergy Clin Immunol. 2016;138(1):200-209.e8.

8. Sloand EM, Pfannes L, Chen G, Shah S, Solomou EE, Barrett J, et al. CD34 cells from patients with trisomy 8 myelodysplastic syndrome (MDS) express early apoptotic markers but avoid programmed cell death by up-regulation of antiapoptotic proteins. Blood. 2007;109(6):2399-405.

9. Olnes MJ, Sloand EM. Targeting immune dysregulation in myelodysplastic syndromes. JAMA. 2011;305(8):814-9.

10. Choi J, Ritchey J, Prior JL, Holt M, Shannon WD, Deych E, et al. In vivo administration of hypomethylating agents mitigate graft-versus-host disease without sacrificing graft-versus-leukemia. Blood. 2010;116(1):129-39.

11. Lu R, Wang P, Parton T, Zhou Y, Chrysovergis K, Rockowitz S, et al. Epigenetic perturbations by Arg882-mutated DNMT3A potentiate aberrant stem cell gene-expression program and acute leukemia development. Cancer Cell. 2016:30(1):92-107.

12. Fuster JJ, MacLauchlan S, Zuriaga MA, Polackal MN, Ostriker AC, Chakraborty R, et al. Clonal hematopoiesis associated with TET2 deficiency accelerates atherosclerosis development in mice. Science. 2017;355(6327):842-7.

13. Zhang $X$, Su J, Jeong $M$, Ko M, Huang Y, Park HJ, et al. DNMT3A and TET2 compete and cooperate to repress lineage-specific transcription factors in hematopoietic stem cells. Nat Genet. 2016;48(9):1014-23.

14. Pan F, Weeks O, Yang FC, Xu M. The TET2 interactors and their links to hematological malignancies. IUBMB Life. 2015:67(6):438-45.

15. Basiorka AA, McGraw KL, Eksioglu EA, Chen X, Johnson J, Zhang L, et al. The NLRP3 inflammasome functions as a driver of the myelodysplastic syndrome phenotype. Blood. 2016;128(25):2960-75.

\section{Publisher's Note}

Springer Nature remains neutral with regard to jurisdictional claims in published maps and institutional affiliations.
Ready to submit your research? Choose BMC and benefit from:

- fast, convenient online submission

- thorough peer review by experienced researchers in your field

- rapid publication on acceptance

- support for research data, including large and complex data types

- gold Open Access which fosters wider collaboration and increased citations

- maximum visibility for your research: over $100 \mathrm{M}$ website views per year

At BMC, research is always in progress.

Learn more biomedcentral.com/submissions 